\title{
Problems and Strategies on Cultivating Excellent Vocational Education Teachers in Local Normal University
}

\author{
Xuhong Wang1, Xue Wang2 \\ ${ }^{1}$ Chengdu Normal University, Chengdu, China \\ ${ }^{2}$ Yuhuan Secondary Vocational and Technical School of Zhejiang Province, Yuhuan, China \\ Email: 706975889@qq.com
}

How to cite this paper: Wang, X. H., \& Wang, X. (2021). Problems and Strategies on Cultivating Excellent Vocational Education Teachers in Local Normal University. Creative Education, 12, 2167-2179. https://doi.org/10.4236/ce.2021.129166

Received: August 31, 2021

Accepted: September 23, 2021

Published: September 26, 2021

Copyright ( 2021 by author(s) and Scientific Research Publishing Inc. This work is licensed under the Creative Commons Attribution International License (CC BY 4.0).

http://creativecommons.org/licenses/by/4.0/

(c) (i) Open Access

\begin{abstract}
The vocational education plays an important role in Chinese education system. Under the guidance of government, local normal universities enter the field of vocational education in response of this reform process. It is not only the strategic demand of higher education reform, but also the internal demand of the transformation and development of local normal universities. The new industrial revolution has put forward higher requirements for the abilities of vocational education teachers. This paper adopts SWOT method to analyze the internal and external circumstances and challenges to local normal university in cultivating excellent vocational education teachers. Appropriate strategies are discussed for local normal university to cultivate excellent vocational education teachers. Based on normal education, through major construction and multi-dimensional collaboration, excellent vocational education teachers with "normal nature, academic nature and professional nature" will be trained. The pattern of "one body with two wings" will not only promote scientific and sustainable development, but also enhance the local normal university's core competitiveness and the ability to serve the society effectively.
\end{abstract}

\section{Keywords}

Local Normal University, Vocational Teaching Staff, SWOT Analysis, Integration of Education and Industry

\section{Introduction}

Accelerating the development of modern vocational education is a major strategic decision made by the CPC Central Committee and the State Council. The 
Ministry of Education, together with the National Development and Reform Commission and other departments, has worked out the Plan for the Construction of a Modern Vocational Education System (2014-2020), in which government encouraged local universities to participate in the construction of the vocational education system (2014). The National Vocational Education Reform Implementation Plan issued by the State Council in 2019 clearly proposes that multi-measures should be taken simultaneously to build a "double-qualified" teaching staff, which is the key and guarantee to accelerate the modern vocational education and comprehensively improve the quality of talent cultivation. With the support of national policies, a series of explorations and practices have been carried out in the reform of vocational education in China. Relevant systems have been improved gradually, the number of the teachers is growing, the supplydemand structure tends to be balanced, and the proportion of high-quality teachers with double skills and excellent professional skills has gradually increased. Facing the strategic needs of national education reform and development and "One Belt and One Road", it is an inevitable choice for local normal university to join in actively the modern vocational education team, and it is also the internal demand of universities' transformation and development (Zhang, 2018b).

With the development of vocational education, vocational schools face many problems in teaching staff: the big gap between the existing teachers and the actual demand, whether in terms of quantity or comprehensive competence. In China, more than 30 colleges and universities train vocational teachers. But the fact is that it has no sufficient attraction to the recruit students and it is difficult to be a vocational education teacher after graduation. The university's dilemma is a challenge to the training and construction of teachers in vocational education. The purpose of this paper is to explore effective strategies to make local normal university perform better in vocational education.

\section{Sample and Method}

As a newly-built university, Chengdu Normal University has done experiment in the major of Automobile Service Engineering and the major of Digital Media Technology to cultivate vocational education teacher systematically and professionally since 2016. During the process of cultivation, there are many difficulties and the performance is not ideal. Semi-structured in-depth interviews with some teacher participants were conducted in Chengdu Normal University. Open-ended questions include the structure of student resources, teacher quality, curriculums, training resources, output quality and so on. Students enrolled in 1st, 2nd and 3rd grades forums were held. Contradictions, challenges, data, opinions and suggestions were collected by individual and group interviews. Based on this experiment and experience, the current paper aims to break new ground in cultivating excellent vocational education teacher by investigating present situation in local normal university using strength-weakness-opportunity-threat (SWOT) analysis method. 


\section{Current Situation and Attribution Analysis: Strength, Weakness, Opportunity and Threat}

\subsection{Strength}

For many years, local normal university has served local basic education and accumulated rich theoretical and practical experience in teaching skills. A mature system on cultivating teaching skills effectively has come into being after years of practice. In normal university, majors and courses are set according to traditional disciplines and requirements. Influenced by traditional teaching model, local normal university attaches importance to theoretical teaching and the cultivation of general literacy. Under the strong atmosphere of normal education, students' normal nature has been fully cultivated. And this has laid a solid theoretical foundation for students' sustainable development in future.

With the rapid progress of society, the development of information technology has broken the traditional teaching mode in universities. To adapt to the new tendency in higher education informatization, local normal university promotes the deep integration of information technology and education and teaching. The wide application of flipped class, micro-class and MOOC makes teaching methods more flexible and diverse. Especially under the epidemic situation of COVID-19, networked and information-based education has become the common way. With the deep integration among information technology and education, great changes have taken place among the content, means, methods, evaluation and every aspect in education, which gradually meet the needs of teachers and students for joint learning, cooperative learning, inquiry learning and individualized learning. And on this basis, a new educational model is established. Efficient network teaching and information management promote the exploration of blended learning. It improves not only normal university students' ability of applying information technology in learning, but also the efficiency of university's management and service comprehensively.

\subsection{Weakness}

\subsubsection{Single Funding Source}

Modern simulation lab, training resources and sufficient competent teachers, these are the basic guarantee for vocational education teacher cultivation. And the existing hardware and software facilities in local normal university are relatively backward, which can't meet the demands of vocation cultivation. Local normal universities are mainly funded by local governments, and the single funding source limits university's further development. Universities and enterprises are not closely connected, university-enterprise collaborative platform exists nominally. As a result, there is mismatch between the skills supplied in local normal university and the specific industry needs. Teaching skills are as important as professional application skills. However, the limited experimental condition in the university is mainly for basic teaching skills and can't meet the needs of students' professional skills training. Lack of professional practice leads to 
poor operational ability. The off-campus practice bases are mainly located in primary and secondary schools, and there is no connection with the corresponding secondary vocational schools. During the internship, there is no special guidance for vocational education students to follow. The moral education management ability, class-control ability and practice instruction ability of vocational teachers can't be experienced and improved effectively through the traditional mode (Li, 2019).

\subsubsection{Shortage of Competent Teachers}

The importance of teachers is widely acknowledged at all level. The competency of vocational education students is to great extent influenced by the quality of vocational education teachers. Students are expected to graduate with the ability to combine industry with vocational education, integrate theory with practical experience, and develop university-based courses (Zhang, 2018a). In local normal university, most teachers are engaged in teaching directly after graduation. Lack of practical experience in the industry, skill shortages and rapidly changing skill requirements, many young teachers cannot really integrate theory with practice. It weakens the professionalism of vocational education to a certain extent. Outdated curriculum, insufficient training resources affect the quality of teaching. Faced with this defect, local normal university takes various measures to make up for the shortage. However, the effect is not satisfactory. Generally professional teachers have to finish a large number of teaching and research tasks. In order to benefit more teachers, training is generally scheduled in winter or summer vacations. Such training programs are short-term. The training content is popular, such as production line visit, discussion and some special lectures. Without diverse experiences, it is difficult for professional teachers to guide. The professional competence of teachers has not been effectively improved. Enterprises lack enthusiasm to participate in the training of vocational education teachers. In fact, workplace mentor support is a crucial aspect in facilitating workplace learning (Maxwell, 2014). National policies and external safeguards are inadequate which makes the cooperation more formalized $(\mathrm{Wu}$, 2019). On one side, it is difficult for universities to invite the technical backbone of enterprises to be part-time teacher for a long time. On the other side, opportunities are very limited for teachers to practice and learn in enterprise's post. Troubled by the contradiction, the local normal university will be in the predicament of shortage of capable teachers with up-to-date competence for a long time.

\subsubsection{Unsatisfactory Employment Situation}

According to the statistics of the employment situation of undergraduates majoring in Automobile Service Engineering in Chengdu Normal University in recent three years, less than 10 percent undergraduates signed contracts with the corresponding vocational school, and fewer are left to teach. In university, more than one third students in this major want to change to another major. There are several factors that affect vocational education students' career choice. Firstly, 
for a long time, vocational schools are in a low position in society. Students in normal university have a low sense of identity to vocational education, they don't want to work in such vocational schools after graduation. As a result, the resource of vocational education teachers is lost and the return of cultivating investment is low (Wang, 2018). Secondly, with the development of vocational education in China, vocational schools put forward higher requirements for professional teachers. Teachers must have a master's degree. As such the undergraduates from local normal university are not qualified to teach in these vocational schools. At present, the teachers in secondary vocational and vocational colleges are mainly graduate students. Thirdly, although the number of vocational schools has gradually increased, the number is still not as large as that of primary and secondary schools. There are no secondary vocational schools in rural towns and villages. So vocational schools do not provide enough jobs for students to choose. In addition, vocational education teachers have no equal opportunities in the aspects of higher education, job treatment and promotion.

\subsection{Opportunities}

According to the general idea of the Plan for Popularizing Senior High School Education (2017-2020), the government puts vocational education in a prominent position, attaches equal importance to general education and vocational education. To meet the diverse needs of students and their parents, it is necessary to develop general education and vocational education coordinately. In the future, 50 percent of high school students will graduate from vocational high schools. That is to say, more vocational teachers with excellent professional competence are needed. The integration of global economy and politics and the upgrading of national industrial structure have put forward higher requirements for the competence of vocational education teachers. Under the concept of lifelong education, the state has established a relatively complete system of postservice training for primary and secondary school teachers. A series of "national training projects" and "provincial training projects" have effectively promoted professional competence and overall quality in primary and secondary school teachers. Comparatively speaking, owing to the complicated and diversified subjects, the training system of vocational education is not perfect and effective. Their objectives are not clear, the organization structure is not reasonable and the mechanism based on cost and interest sharing has not yet been established (Che, 2016). In view of the huge demand of vocational education teachers and the absence of post-vocational training, there is still much to be explored by local normal university.

\subsection{Threats}

\subsubsection{Intensifying Competition}

With national relevant policies and incentive structures, more and more universities will enter the field of vocational education, and the competition is bound to intensify. These universities, especially those with first-class disciplines, gen- 
erally have solid foundation, long history, first-class teaching staff and obvious disciplinary advantages. These universities could provide better platform for the further improvement of vocational education students. The diverse and multidisciplinary academic environment has a good influence on students. It is conducive to broaden vision and the scope of knowledge. Their advantages can't be surpassed by other ordinary universities. Moreover, there are 49 universities cultivating master level vocational education students. Therefore, the students graduated from local normal university are not as good as those with master degree in terms of academic quality and comprehensive ability, and are inferior to those of higher vocational technical colleges in terms of practical ability.

\subsubsection{Cultural Prejudice}

In fact, the deeper threat is the deep-rooted prejudice. The prejudice exists both inside and outside the school. Under the current policy, most universities are still concerned about the transition to vocational and technical education. Quite a number of teachers believe that the transformation of local normal universities into modern vocational education system would lower the grade of universities. There is also a bias against vocational education among the society. People are not satisfied with vocational education, and vocational education has been defined as "secondary education" for a long time (Wu, 2019).

\section{Strategies}

Intelligent manufacturing has brought great changes to the pattern of industrial production, and the modern industrial production mode is becoming highly digital, personalized, networked and flexible ( $\mathrm{Hu}, 2018)$. Vocational teachers need to be well qualified to meet the growing social needs and changes. To be compound and innovative vocational education teachers with up-to-date competences have gradually become the tendency for modern vocational education teaching staff (Zhang, 2018a). Funds, infrastructure and technological resources would facilitate the successful cultivation. Therefore, the local normal university needs to make plan for the top-level design and comprehensive reform. Besides self-improvement of the university, a powerful and favorable external support is necessary. By relying on the internal and external efforts can we cultivate outstanding vocational education teachers with international, compound and innovative qualities effectively.

\subsection{Top Level Design with Foresight}

In the post-COVID-19 epidemic era, local normal university should first clarify the trend of vocational education in order to find the focus and breakthrough of development. Due to information technology and network technology, modern industrial and vocational schools have higher requirements, so the connotation of competent teachers in vocational education has made corresponding changes. It is necessary not only to broaden the breadth and depth of professional knowledge, but also to enhance the practical ability and innovative teaching ability 
under the digital mode.

To improve the efficiency of the cultivation project in local normal university, it is significant to broaden horizons, update ideas and combine international successful experience. In university, top-level planning should be designed from different perspectives. From the perspective of the local area, the local normal university should put emphasis on the unique feature of cultivation, which could ensure the overall quality and differentiated advantages of vocational education students (An, 2019). From international perspective, the objectives and standards of cultivation should be in line with international standards, which is conducive to the international exchanges. Under the circumstances of "One Belt and One Road", scopes and fields of collaboration continue to expand in the worldwide. "One Belt and One Road" not only indicates a new direction, but also provides a new platform for promoting China's high-quality vocational education to the world.

\subsection{Fostering Internal Literacy and First-Class Majors}

In the post-epidemic period, the concept of "double-competent" teachers has been endowed with new connotation, and the training system of vocational education teachers will inevitably undergo a fundamental transformation from concept to paradigm to culture (Che, 2016). In order to make a breakthrough in the field of vocational education, the local normal university must overcome some misunderstandings and strengthen self-construction.

First is to select suitable majors for vocational teacher education. Based on the integration of resource sharing advantages, the university should rearrange the existing majors. Normal education oriented to basic education is the cornerstone of developing vocational education in the local normal university. The vocational education majors should be established according to the national strategy and the needs of local economic development, which is different and advantageous from those in other engineering universities (Sun, 2020).

Second is to concentrate on major construction and cultivate first-class majors. The training program should be guided by OBE (outcome-based education) concept. Cultivation goals should be consistent with industry needs, the graduation requirements are determined by cultivation goals, the cultivation mode is determined by the knowledge structure. Professional education, vocational education and teacher education are integrated in the curriculum system by this way. It is believed that such curriculum system could ensure cultivation of comprehensive literacy, professional ability and career direction as a whole (Che, 2016). But that is not enough. According to the core competence and quality requirements of vocational education students, the standard of all details and curriculums should be clarified to achieve the coverage of vocational competence. On the one hand, the cultivation of excellent vocational education teachers needs external aid to provide advanced ideas and technical support; on the other hand, its core is still internal training in university. Only by strengthening 
school-based training can we truly cultivate excellent teachers that meet the needs of our school, region and industry (Che, 2016).

Third is to build a monitoring platform based on vocational teachers' education quality and big data. To improve quality effectively, it is necessary to introduce multiple subjects to participate in process evaluation and conclusive evaluation. Multi-dimensional and multi-perspective self-assessment should be fulfilled by normal monitoring and qualification certification, by on-line monitoring and field investigation, by quantitative analysis and qualitative evaluation. At the same time, the achievement of training objectives, the adaptability to social needs, and the satisfaction of students and employers are important basis for evaluating education quality. Therefore, on the basis of self-evaluation, continuous external evaluation from society and industry is considered as an excellent method to estimate efficiency and quality of vocational education.

Fourth is to improve the supporting measures for teachers' training. Professional teachers are the key to the adjustment of training program, the reform of curriculum setting and teaching content. If the quality of teachers is still at the level of the inherent vocational education, the quality-oriented education to cultivate students' independent thinking is impossible to be realized (Cai, 2021). In National Program for Implementation of Vocational Education Reform, teachers are required to attend practical training at the base or workplace at least one month a year. The local normal university should take measures to implement this requirement effectively. Vocational teacher educators need to be well qualified and with up-to-date competences as well as keep developing themselves to meet the rapid social changes and needs. To motivate teachers to participate in training activities, it is necessary to keep sustained and stable financial support and incentive policy. Especially to local normal university, the absence of favorable economic policy has been cited as a limitation to development.

\subsection{Various Collaborations to Strengthen University's Ability Serving the Society}

\subsubsection{Collaboration between Schools and Universities}

There is no mutual benefits among different educational institutions, which affects the depth of collaboration between them to a certain extent. In secondary vocational schools, it is seldom considered whether students' knowledge reserve could lay a solid foundation for their future study and development. And in university, there is no research about students' early professional foundation. This leads to knowledge duplication and gap in university curriculums, which makes it difficult to guarantee the teaching quality. So the knowledge linkage among different stages is particularly important to enhance the vocational education and training quality outcome.

Now, the students from higher vocational colleges or secondary vocational schools are weaker in terms of comprehensive ability and cultural knowledge foundation, but stronger in practice. Insufficient communication resulted in lower efficiency. Keeping touch with schools initiatively is a good way to know stu- 
dents' knowledge foundation and schools' evaluation system. Only by breaking the separate situation and barriers between the local normal university and schools, can we avoid the knowledge repetition and disconnection. From secondary vocational schools to vocational colleges to local normal university, the difficulty of knowledge increases gradually. It truly reflects the orderliness, continuity and conformity of the curriculum setting. Exploring segmental cultivation mode is not a simple knowledge superposition and the extension of learning time. By collaboration, schools and local normal university not only take advantages of each party, but also solve various problems arising in the cohesion process coordinately. At the same time, in order to maintain the independence and integrity of different stage, school and university's target position should be clear and different. Schools, vocational colleges and local normal universities are interdependent and influenced each other. Effective mechanism of long-term collaboration between local normal university and student source schools can not only guarantee the selection of high-quality students, but also facilitate the efficient cultivation of excellent vocational education teachers at the undergraduate stage. At the same time, good collaboration could open up the employment channels for students to return to teach in these vocational schools after graduation.

\subsubsection{Collaboration between Universities and Enterprises}

In Germany, Japan and Australia, their excellent vocational education is inseparable from good collaboration with domestic industries. School-enterprise cooperation and the integration of industry and education are the necessary links in cultivating vocational education teachers.

Firstly, the local normal university should seek opportunities for collaboration initiatively. In the era of openness and sharing, universities should understand the role of the market and enterprises, contact with relevant enterprises actively, and strive to seek resources from all walks of life to participate in cultivating vocational education teachers. It is not enough to keep in close contact with the education authorities. The local normal university must strive for local government's policy support and financial aid. On the basis of equality, independence, and mutual benefit, it is possible to build a community composed of the local government, local industry, enterprises and universities. With the continuous improvement of the collaboration mechanism, joint cultivating vocational education teachers by the three parties could be carried out effectively.

Secondly, enterprise's enthusiasm is another important factor. In fact, there are many challenges to the collaborations. These challenges include an absence of workplace mentors, limited access to activities, a lack of clear policies to support collaborations, the cultural difference between university and industries and inadequate resources (Arinaitwe, 2021). Due to these challenges, the result of collaboration depends on the partners' willingness and ability to overcome the numerous constraints. In the absence of policies, industries and enterprises may not feel obliged to participate. In recent years, government has issued many preferential policies to motivate enterprises to participate in vocational education, 
while cost-benefit analysis is the critical factor that affects enterprise's enthusiasm. Only when the collaborations benefit both parties in the joint affair, mutual trust and common understanding could be promoted. It is difficult for the local normal university to attract large enterprises to participate in industryuniversity collaboration because their own advantages are not prominent. Therefore, the local normal university must attach importance to the collaboration with local small and medium-sized enterprises (Wang, 2020). Under the influence of COVID-19, the survival and development of small and medium enterprises have been threatened seriously. The local normal university should provide them with theoretical guidance and technical assistance actively, so that enterprises can truly realize the necessity of industry-academic cooperation. With collaboration platform, smooth channel for communication and strong desire for collaboration, can the university and enterprise collaborate effectively and achieve mutual assistance and common development. In addition, personal relationship is a key enabler for collaboration, especially with small and medium enterprises. The partners in the collaboration will feel safer establishing linkages with people who are accustomed to their work, expectations and interests (O'Reilly \& Cunningham, 2017).

Thirdly, the industry-academy collaborative education project backed by the Ministry of Education is building a bridge for the extensive collaboration between local normal university and distant enterprises. Generally speaking, enterprises tend to develop collaborative links with those research institutions in near geographical locations. The closer the two partners are, the easier it is to interact and moderate uncertainties during collaboration (Johnston \& Huggins, 2016). Geographical proximity could reduce running costs and allow for platforms for interaction as well as facilitates the spread of information and on-site guidance, which increase the likelihood of collaboration. With the continuous integration of information technology, industry and education, geographical location has little influence on collaboration. The collaborative education project of industry and education has broadened the collaborators for universities, and the collaboration with distant enterprises has greatly broadened the horizons and perspectives of professional teachers, which is conducive to promote research beyond local boundaries (Muscio, 2012). In this way, an all-round collaboration pattern has come into being with experience exchange, information sharing, training guidance and mutual support, joint construction of training bases and new curriculum development. With the promotion of exchanges and collaboration between universities and enterprises, enterprises are deeply involved in talent cultivation. They work together on setting the learning missions for students. And as mentors, they help students make a connection between knowledge in class and application in workplace. The enterprise's dominant position and advantages have been fully displayed, which not only improves the professional ability of part-time teachers, but also enhances its social visibility (Wang, 2020). The collaboration of industry and education could solve two major difficulties in local normal university: training base and competence teachers, which 
is effective to improve the technical practice ability of vocational education students. With common interests, destiny and responsibility, university-enterprise community comes into being, the virtuous circle of integration of industry and education can be firmly guaranteed and collaborative education can be promoted smoothly.

\subsubsection{International Collaboration}

Today, with the acceleration of economic globalization and the continuous advancement of "One Belt and One Road", international ability has gradually become a necessary ability for vocational education teachers. So the local normal university must attach importance to the cultivation of students' ability to communicate in multiple languages, enhance cross-cultural awareness, improve crosscultural communication and teaching ability ( $\mathrm{Hu}, 2018)$. The local normal university should go out and introduce international advanced technology and excellent foreign vocational education teachers. The international level of the local normal university can be improved by learning the advanced vocational education concept and teacher-training mechanism from developed countries. At the same time, relying on "One Belt and One Road", it is necessary to seek opportunities to run schools jointly with high quality vocational education abroad, and explore the mode of mutual exchanging with foreign vocational education institutions, so as to provide learning opportunities for our professional teachers and students. With the help of international joint programs, the local normal university can not only enhance its influence in the world, but also realize the "one body with two wings" development strategy.

\section{Conclusion}

Based on teacher-education advantage, the local normal university could improve its core competitiveness and ability to serve the society by integrating internal resources, optimizing the structure, and developing normal education and vocational normal education at the same time. The local normal university's sustainable development depends on scientific planning. However, the cultivation of the vocational education teachers is a multidisciplinary integration process; its quality will be affected by many factors. The lack of some collaborative mechanism will make it uneasy to coordinate the responsibilities, powers and interests of different subjects at the same time. And without some collaborative mechanism, it is difficult to effectively integrate the resources among different industries, enterprises, colleges and vocational schools. It is impossible to integrate "normal nature, academic nature and professional nature" organically throughout the cultivation process. Therefore, cultivating excellent vocational education teachers with "three characteristics" can't be effective through short time academic education and various qualifications. To be an excellent teacher needs to accumulate more practice and continuous reflection and learning in working. Personal efforts cannot be separated from government support. With stable and favorable policy guidance, it is essential to set up a collaborative education me- 
chanism among universities, vocational colleges, industries and enterprises, smooth the channels for cultivating teacher, create an ecological environment for career development, and improve the treatment of technical and skilled personnel to enhance the recognition and attractiveness of vocational education at the same time.

In a word, vocational education has a bright future. There is much more to do.

\section{Funding}

This work was supported by Teaching Research and Reform Project of Chengdu Normal University 2021 (2021JG27).

\section{Conflicts of Interest}

The authors declare no conflicts of interest regarding the publication of this paper.

\section{References}

An, P. D. (2019). Innovative Construction of Vocational Education Teacher Training Path Based on Japanese Experience and History. Education and Career, 86, 86-92.

Arinaitwe, D. (2021). Practices and Strategies for Enhancing Learning through Collaboration between Vocational Teacher Training Institutions and Workplaces. Empirical Research in Vocational Education and Training, 13, 1-22. https://doi.org/10.1186/s40461-021-00117-z

Cai, J. G. (2021). On the Vigilance of Vocational Education Degradation from Discipline to Diploma. Guangming Daily, 2021-4-29(02).

Che, M. C. (2016). Summary of the Forum on Teaching Staff Construction in Modern Vocational Education. Chinese Vocational and Technical Education, No. 34, 54-57.

Hu, M. B. (2018). Inheritance and Reform: The Quality Assurance of Vocational Teachers in the European Union in the 21st Century-Analysis Based on the Training of Vocational Teachers in Germany, Finland and Austria. Vocational and Technical Education, 39, 74-77.

Johnston, A., \& Huggins, R. (2016). Drivers of University-Industry Links: The Case of Knowledge-Intensive Business Service Firms in Rural Locations. Regional Studies, 50, 1330-1345. https://doi.org/10.1080/00343404.2015.1009028

Li, K. F. (2019). Training Mode for the Core Competence of "Three Abilities in One" Education for Vocational Teachers. Vocational Education, 18, 61-63.

Maxwell, B. (2014). Improving Workplace Learning of Lifelong Learning Sector Trainee Teachers in the UK. Journal of Further and Higher Education, 38, 377-399. https://doi.org/10.1080/0309877X.2013.831036

Muscio, A. (2012). University-Industry Linkages: What Are the Determinants of Distance in Collaborations? Papers in Regional Science, 92, 715-739.

https://doi.org/10.1111/j.1435-5957.2012.00442.x

O’Reilly, P., \& Cunningham, J. (2017). Enablers and Barriers to University Technology Transfer Engagements with Small and Medium-Sized Enterprises: Perspectives of Principal Investigators. Small Enterprise Research, 24, 274-289.

https://doi.org/10.1080/13215906.2017.1396245

Sun, L. (2020). Reforming Orientation and Development Trend of the Construction of 
Vocational Education Teachers in the New Era. Chinese Vocational and Technical Education, 35, 36-40.

The Notice of the Ministry of Education and Other Six Departments on the Issuance of the Plan for the Construction of a Modern Vocational Education System (2014-2020). http://www.moe.gov.cn/srcsite/A03/moe 1892/moe 630/201406/t20140623 170737.html

Wang, W. (2018). Difficulties in Teacher Training of Vocational Education under the Background of "Double First-Class". China Education Daily, 2018-05-22(09).

Wang, X. H. (2020). Reflections on Current Situation and Development of Industry-University-Research Cooperative Education in Local Normal Universities. Journal of Chengdu Normal University, 36, 29-34.

Wu, J. (2019). The Achievement Problem and Reform Path of Vocational Education in the New Era-Based on the Interpretation of the 19th National Congress of CPC Report. Higher Vocational Education Exploration, 18, 57-59.

Zhang, H. H. (2018a). Exploration and Innovation in the Cultivation of Vocational Education Teachers in China from 1978 to 2018. Vocational and Technical Education, 39, 42-47.

Zhang, L. (2018b). The Dilemma and Breakthrough of Local Application-Oriented Undergraduate Colleges' Active Integration into Modern Vocational Education System. Education and Career, 17, 47-50. 